\title{
Pain Catastrophizing and Kinesiophobia Affect Return to Sport in Patients Undergoing Hip Arthroscopy for the Treatment of Femoroacetabular Impingement
}

\author{
Robert B. Browning, M.D., Ian M. Clapp, M.S., Thomas D. Alter, M.S., \\ Benedict U. Nwachukwu, M.D., M.B.A., and Shane J. Nho, M.D., M.S.
}

Purpose: To assess whether pain catastrophizing and kinesiophobia affect return to sport (RTS) or clinically significant outcome (CSO) achievement in patients undergoing hip arthroscopy for the treatment of femoroacetabular impingement (FAI). Methods: Patients undergoing primary hip arthroscopy at a single institution between January 2017 and March 2017 were prospectively enrolled. Patients received the Tampa Scale of Kinesiophobia-11 (TSK-11) and Pain Catastrophizing Scale (PCS) questionnaires preoperatively, 3 weeks, 6 weeks, 3 months, 6 months, and 1 year postoperatively. Patients also received the Hip Outcome Score Sport-Specific (HOS-SS) questionnaire preoperatively and 1 year and 2 years' postoperatively. An RTS questionnaire was completed at final follow-up. Bivariate correlations were conducted between PCS and TSK-11 scores and RTS status and achievement of CSOs of HOS-SS, based on patient acceptable symptom state (PASS) and substantial clinical benefit (SCB). Results: Fifty-eight patients with an average age of $31.9 \pm$ 12.2 and body mass index of $24.0 \pm 3.8$ participated in sport prior to surgery and were included in the study. Forty-two $(72.4 \%)$ patients returned to sport at $10.5 \pm 7.1$ months following surgery. There was a significant reduction in TSK-1 1 and PCS scores at 1 -year follow-up (TSK-11, $26.1 \pm 6.0$ vs $18.6 \pm 6.1, P<.001$; PCS, $17.7 \pm 10.5$ vs $4.3 \pm 6.8, P<.001$ ) as well as a significant improvement in HOS-SS $(P<.001)$. At 1 year, fair correlations were demonstrated between PCS $(\mathrm{r}=$ $-0.446, P=.010)$ and TSK $(\mathrm{r}=-0.330, P=.029)$ scores and RTS. Patient who returned to sport had lower PCS $(8.5 \pm$ 11.7 vs $3.0 \pm 3.7, P=.010)$ and TSK- $11(21.8 \pm 8.5$ vs $17.6 \pm 4.8, P=.029)$ scores at 1 year. At 1 -year follow-up, PCS $(\mathrm{r}=$ $-0.572, P=.001)$ and TSK-1 $1(\mathrm{r}=-0.441, P=.012)$ scores demonstrated fair correlations with achieving PASS for HOSSS at 2-year follow-up. Conclusions: Patient kinesiophobia and pain catastrophizing at 1-year follow-up were negatively correlated with RTS and achievement of a CSO in sport-related activities at 2-year follow-up. Level of Evidence: III, prospective cohort study.

$\mathbf{F}$ emoroacetabular impingement (FAI) is a common cause of pain and dysfunction in athletes of all sports and ability levels. ${ }^{1-3}$ Hip arthroscopy is widely used to treat FAI and has demonstrated improved clinical outcomes in young, active patients at

\footnotetext{
From the Section of Young Adult Hip Surgery, Division of Sports Medicine, Department of Orthopedic Surgery, Hip Preservation Center, Rush University Medical Center, Chicago, Illinois (R.B.B., I.M.C., T.D.A., S.J.N.); and Department of Orthopaedic Surgery, Hospital for Special Surgery, New York, New York (B.U.N.), U.S.A.

The authors report the following potential conflicts of interest or sources of funding: B.U.N. reports IP royalties from Remote Health, outside the submitted work. S.J.N. reports nonfinancial support from AlloSource, other from the American Orthopaedic Association and American Orthopaedic Society for Sports Medicine, nonfinancial support from Arthrex, other from Arthroscopy Association of North America, nonfinancial support from Athletico, DJ Orthopaedics, ConMed Linvatec, and Miomed, personal fees from Ossur, nonfinancial support from Smith $\theta$ Nephew, and personal fees from Springer and
}

medium- to long-term follow-up. ${ }^{4-8}$ Furthermore, athletes have returned to sport at a high rate, and many reach preinjury levels following hip arthroscopy. ${ }^{9-13}$ Despite the majority of patients reaching clinical improvement, there continues to be a number

Stryker, outside the submitted work. Full ICMJE author disclosure forms are available for this article online, as supplementary material.

Received October 1, 2020; accepted March 30, 2021.

Address correspondence to Ian M. Clapp, M.S., Department of Orthopedic Surgery, Rush University Medical Center, 1611 W Harrison St, Chicago, IL 60612.E-mail: thomas.alter137@gmail.com

(C) 2021 THE AUTHORS. Published by Elsevier Inc. on behalf of the Arthroscopy Association of North America. This is an open access article under the CC BY-NC-ND license (http://creativecommons.org/licenses/by-nc-nd/4.0/). 2666-061X/201614

https://doi.org/10.1016/j.asmr.2021.03.014 
of patients who are less likely to return to sport (RTS) at a preinjury level. Clinical outcomes and speed of recovery are highly influenced by patient-specific factors, including age, sex, obesity, and osteoarthritis. ${ }^{14,15}$ Recently, multiple studies have shown that mental disorders negatively influence the rehabilitation process and overall outcomes following various orthopaedic surgeries. ${ }^{16-23}$

Psychological traits have shown to influence pain interpretation and play a more significant role than initially believed. ${ }^{24,25}$ Leeuw et al. ${ }^{26}$ explained the "fear avoidance model of musculoskeletal pain" and its role in patient outcomes. Kinesiophobia is an exaggerated fear of physical movement arising from the belief of susceptibility to injury, and pain catastrophizing is an excessive or inappropriate response to that pain. Pain catastrophizing has been objectively measured using the Pain Catastrophizing Scale (PCS), ${ }^{27}$ a validated scoring system, with greater scores indicating greater catastrophizing. The Tampa Scale for Kinesiophobia (TSK) or the shorter validated Tampa Scale for Kinesiophobia-11 (TSK-11) ${ }^{28}$ can objectively quantify kinesiophobia, with greater scores indicating a greater degree of pain-related fear. Both of these psychological traits negatively affect a patient's ability to participate in rehabilitation and RTS. ${ }^{19,26,29-31}$ Lentz et al. ${ }^{32}$ studied 46 patients who had undergone anterior cruciate ligament reconstruction and found that patients with greater pain-related fear of movement and reinjury according to the TSK-11 at 6 months postoperatively were less likely to return to preinjury level despite no difference in pain. In a systematic review of anterior cruciate ligament reconstruction by Nwachukwu et al., ${ }^{33}$ fear of reinjury is the most common impediment to successful RTS. Clapp et al. ${ }^{34}$ demonstrated that PCS scores at 1 year postoperatively were significantly greater in patients who failed to achieve a minimal clinically important difference (MCID), but TSK-1 1 scores did not influence MCID achievement. Although MCID is most commonly used to demonstrate improved patient outcomes following hip arthroscopy, Patient Acceptable Symptom State (PASS) and substantial clinical benefit (SCB) may be more indicative of an athlete's ability to RTS at a high level, as they are harder to achieve than MCID. ${ }^{33}$ PASS and SCB may be more useful markers for determining readiness to RTS at a high level. ${ }^{2}$

The purpose of this study is to assess whether pain catastrophizing and kinesiophobia affect RTS or clinically significant outcome (CSO) achievement in patients undergoing hip arthroscopy for the treatment of FAI syndrome. We hypothesized that following hip arthroscopy, patients who have lower pain catastrophizing and kinesiophobia levels would have greater rates of RTS and greater rates of achievement of sport-specific CSOs.

\section{Methods}

\section{Patient Selection}

After institutional review board approval, consecutive patients undergoing primary hip arthroscopy between January 2017 and March 2017 for the treatment of FAI by a fellowship-trained surgeon (S.J.N.) were prospectively enrolled in the study at a single institution during their preoperative visit. Patients with clinical and radiographic diagnosis of symptomatic $\mathrm{FAI}^{35}$ failure of nonoperative management after more than 3 months (physical therapy, activity modification, oral antiinflammatory drugs, and for some patients fluoroscopically-guided intra-articular cortisone injection), and completion of RTS survey and 2-year functional outcomes were included in the study. Exclusion criteria consisted of hip arthroscopy for an indication other than FAI, revision hip arthroscopy, previous history of ipsilateral or contralateral hip surgery, undergoing contralateral hip arthroscopy during study enrollment and follow-up, signs of osteoarthritis (Tönnis grade $>1$ ), hip dysplasia (lateral center edge angle $<20^{\circ}$ ), ${ }^{36}$ or a history of pediatric hip disorders (slipped capital femoral epiphysis, avascular necrosis, developmental dysplasia of the hip, etc.).

\section{Surgical Technique and Postoperative Rehabilitation}

All hip arthroscopies were performed in a similar manner using a well described technique by the senior author. ${ }^{37,38}$ Standard anterolateral and mid-anterior portals are established under traction with the aid of fluoroscopic guidance. An interportal capsulotomy is then created and pathology addressed in the central compartment with acetabuloplasty and labral repair as needed. Traction is then released, and a T-capsulotomy performed to access to the peripheral compartment, and femoral osteochondroplasty is performed to address cam morphology and restore femoral head-neck offset. Dynamic examination of the operative leg is then performed to confirm an appropriate resolution of impingement upon completion. Lastly, the capsule is repaired using a suture shuttling system, with capsular plication performed depending on degree of capsular laxity. ${ }^{39}$ All patients underwent a previously described standard 4-phase rehabilitation protocol following surgery. ${ }^{40}$

\section{Kinesiophobia, Pain Catastrophizing, and RTS}

Patients were evaluated at a minimum of 2 years from date of surgery. TSK- $11^{28}$ and PCS $^{27}$ questionnaires were assigned preoperatively and at 3 weeks, 6 weeks, 3 months, 6 months, and 1-year postoperatively. Patients received an RTS survey that recorded if they returned to sport, how long after surgery it took to RTS, the level at which they returned, and the reason for 
failure to return if they were unable to return. Patients also received the Hip Outcome Score Activities of Daily Living (HOS-ADL) ${ }^{41}$ and Sport-Specific (HOS-SS) subscales, modified Harris Hip Score (mHHS), ${ }^{42}$ International Hip Outcome Tool-12 (iHOT-12), ${ }^{43}$ and visual analog scale (VAS) for pain preoperatively and at 1 and 2 years' postoperatively.

Due to athletes demanding significant functional improvement to RTS following hip arthroscopy for the treatment of FAI, literature-defined values for the PASS and SCB were used to quantify achievement of a CSO. The threshold scores for achieving PASS 1 and 2 years' postoperatively were 76.4 and 80.9 , respectively, and for SCB, the threshold scores were 77.9 and 85.8, respectively. ${ }^{44}$

\section{Statistical Analysis}

Noncontinuous variables are reported as frequency statistics whereas descriptive statistics for all continuous variables are reported as mean and standard deviations. All data were screened to determine whether parametric statistical assumptions were met before analysis. In cases of parametric analysis violation, the nonparametric analogue tests were applied. Repeated-measures analysis of variance (ANOVA) to assess whether PCS and TSK score averages differed over the time points, and post-hoc analysis with a Bonferroni adjustment was performed to determine significant differences within the timepoints. Bivariate correlations between RTS and TSK-11 and PCS scores were performed. Independent-samples $t$ tests were used to compare preoperative PCS and TSK score averages between patients returning and not returning to sport. Bivariate correlations between PASS achievement and PCS and TSK-11 scores as well as between SCB achievement and PCS and TSK-11 scores were performed. The strength of association based on $r$ values were interpreted as follows: 0-0.29 (poor), 0.30-0.49 (fair), 0.50-0.79 (moderately strong), 0.801.00 (very strong). ${ }^{45}$ Paired-samples $t$ tests were used to compare preoperative and 2-year postoperative patient-reported outcome scores in patients with FAI. Statistical significance for all analysis was set at $P<$ .05. All statistical analysis was performed using SPSS, version 25 (IBM Corp., Armonk, NY).

\section{Results}

\section{Demographics}

Of 68 patients with 2-year functional outcomes, TSK-11, and PCS scores, 58 patients indicated sports participation before surgery and were included in the analysis. The cohort was majority female $(69.3 \%)$ with an average age and body mass index (BMI) of $31.9 \pm$ 12.2 years and $24.0 \pm 3.8 \mathrm{~kg} / \mathrm{m}^{2}$, respectively.

\section{Kinesiophobia and Pain Catastrophizing}

The TSK-11 and PCS score averages at the 6 time points recorded are summarized in Figure 1. Repeatedmeasures ANOVA demonstrated TSK score averages were statistically significantly different at the different time points over the course of a year ( $\mathrm{F}=67.08$; $P<.001)$. Post hoc analysis with a Bonferroni adjustment revealed that TSK-11 score averages at all time points were significantly lower from preoperative scores $(P<.001)$, with an overall reduction from $26.1 \pm 6.0$ to $18.6 \pm 6.1$ at 1 -year follow-up. However, there were no significant differences between the pairwise comparisons of the scores at any other time points $(P>.05)$. For PCS score averages, repeated-measures ANOVA displayed statistically significant differences at the different time points over the course of a year $(\mathrm{F}=54.08 ; P<$ $.001)$. Post hoc analysis with a Bonferroni adjustment revealed that PCS score averages at all time points were significantly lower from preoperative scores $(P<.001)$, with an overall reduction in PCS scores from $17.7 \pm 10.5$ to $4.3 \pm 6.8$. There were no significant differences between the pairwise comparisons of the scores at any other time points $(P>.05)$.

\section{Return to Sport}

Our cohort consisted of 29 recreational athletes, 9 amateur athletes (team or club, e.g., Amateur Athletic Union), 8 college athletes, 11 high school athletes, and 1 professional athlete. Forty-two patients (72.4\%) returned to sport at an average of $10.5 \pm 7.1$ months following surgery. Of the athletes who did not return, 4 $(6.9 \%)$ noted reasons not due to their hip, $4(6.9 \%)$ noted fear of reinjury, and $10(12.9 \%)$ had physical limitation due to their hip (Table 1). When we compared patients returning to and failing to RTS, there were no significant differences in age, sex, or BMI $(P>.05$ for all) between the groups.

Results of bivariate correlations are in Table 2. Briefly, PCS scores at 6 weeks $(\mathrm{r}=-0.422, P=.009)$ and 1 -year $(\mathrm{r}=-0.446, P=.010)$ follow-up demonstrated fair correlations with RTS, and TSK-1 1 scores at 1 -year follow-up demonstrated fair correlation with RTS $(\mathrm{r}=-0.330$, $P=.029$ ). The results of independent-samples $t$ test between patients returning and not returning to sport are reported in Figures 2 and 3. Patients who returned to sport had lower PCS scores at 6 weeks $(10.1 \pm 9.4$ vs $4.5 \pm 4.1$, $P=.009)$ and 1 year $(8.5 \pm 11.7$ vs $3.0 \pm 3.7, P=.010)$, whereas TSK-11 scores were significantly lower only at 1 year $(21.8 \pm 8.5$ vs $17.6 \pm 4.8, P=.029)$.

\section{Functional Outcomes}

Paired $t$-test analysis of pre- and 2-year minimum postoperative patient-reported outcome score averages for the entire cohort are reported in Figure 4. Patients had significant increases in HOS-ADL, HOS-SS, mHHS, and iHOT-12 and a significant decrease in VAS Pain at 


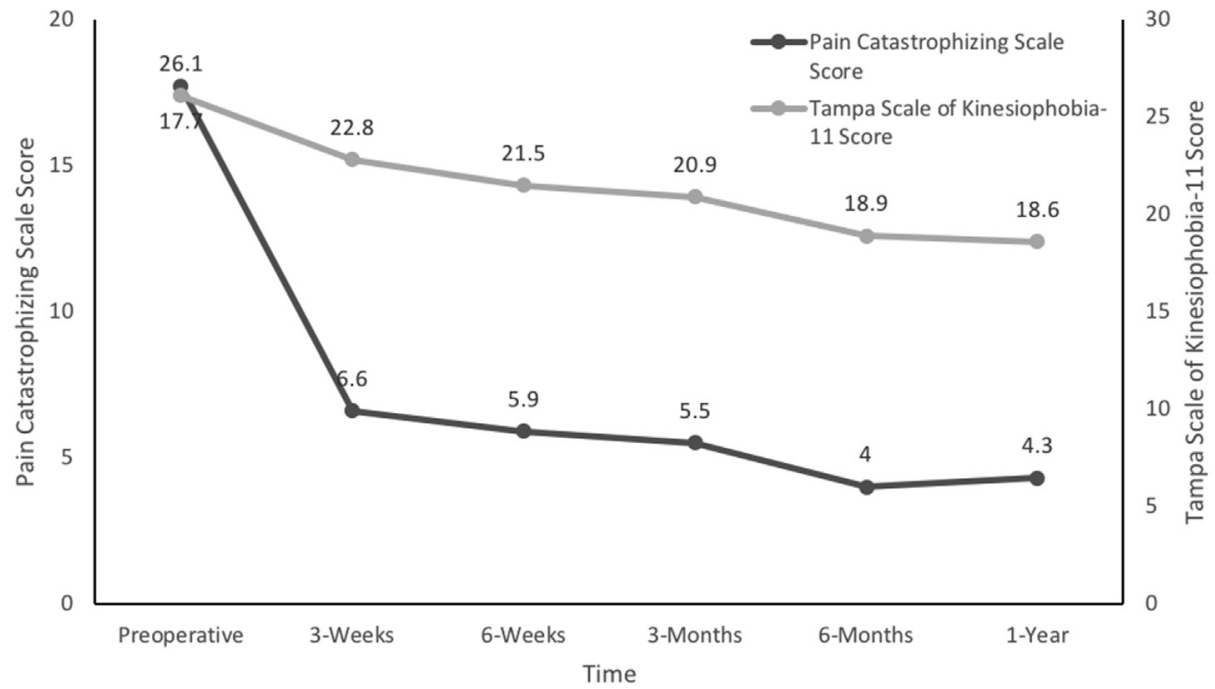

Fig 1. Pain Catastrophizing Scale and Tampa Scale of Kinesiophobia-11 scores at the preoperative, 3-week, 6-week, 3month, 6-month, and 1-year postoperative time points. 2-year follow-up $(P<.001$ for all $)$. To assess clinical significance, we determined the percentage of patients meeting PASS and SCB criteria for HOS-SS. At 1-year follow-up, $74.1 \%$ of patients achieved PASS and $65.5 \%$ achieved SCB, and at 2-year follow-up, $82.8 \%$ and $75.9 \%$ achieved PASS and SCB, respectively. Achievement of PASS for HOS-SS at 1-year follow-up demonstrated fair correlation with 6-week $(\mathrm{r}=$ $-0.466, P=.001)$, 6-month $(\mathrm{r}=-0.311, P=.043)$, and 1-year PCS scores $(\mathrm{r}=-0.493, P=.001)$ and 1 year TSK-11 scores $(\mathrm{r}=-0.318, P=.031)$. HOS-SS SCB achievement at 1-year follow-up demonstrated fair correlation with 6-week $(\mathrm{r}=-0.385, P=.010)$, 3month $(\mathrm{r}=-0.390, P=.011), 6$-month $(\mathrm{r}=-0.463$, $P=.020)$, and 1 -year PCS scores $(\mathrm{r}=-0.429, P=.020)$ as well as 1 -year TSK- 11 scores $(\mathrm{r}=-0.429, P=.002)$ (Table 3). PCS at 3-month $(\mathrm{r}=-0.429, P=.020)$, 6month $(\mathrm{r}=-0.454, P=.010)$, and 1 -year $(\mathrm{r}=$ $-0.572, P=.001$ ) follow-up exhibited fair correlations with achieving PASS for HOS-SS at 2-year follow-up, and TSK-11 scores at 1 -year $(\mathrm{r}=-0.441, P=.012)$ demonstrated a fair correlation with achievement of PASS for HOS-SS at 2-year follow-up. 1-year PCS

Table 1. Return to Sport $(\mathrm{N}=58)$

\begin{tabular}{lr}
\hline Return to sport & $42(72.4 \%)$ \\
$\begin{array}{l}\text { Length of time to } \\
\text { return-to-sport with minimal pain, mo } \\
\text { Return ability level }\end{array}$ & $10.5 \pm 7.1$ \\
$\quad$ Limited effort, limited performance & \\
$\quad$ Unlimited effort, limited performance & $11(15.5 \%)$ \\
$\quad$ Unlimited effort, unlimited performance & $21(36.2 \%)$ \\
Reasons for not returning to sport & $4(6.9 \%)$ \\
$\quad$ Other reasons not due to hip & $4(6.9 \%)$ \\
Fear of reinjury & $10(12.9 \%)$ \\
Physical limitations &
\end{tabular}

demonstrated fair correlation with achieving SCB for HOS-SS at 2-year follow-up $(\mathrm{r}=-0.549, P=.001)$ (Table 4). In addition, 1-year TSK-11 scores at 1-year demonstrated fair correlation $(\mathrm{r}=-0.398, P=.024)$ with achieving SCB for HOS-SS at 2-year follow-up (Table 4).

\section{Discussion}

The main findings of this study are that 42 patients $(72.4 \%)$ returned to sport at an average of 10 months postoperatively, and while both pain catastrophizing and kinesiophobia decreased during the postoperative period, PCS scores at 6 weeks and 1-year and TSK-11

Table 2. Correlation Analysis Between Return to Sport and PCS and TSK-11 Scores

\begin{tabular}{lcc}
\hline & Return to Sport $(r)$ & $P$ Value \\
\hline Preoperative & & \\
$\quad$ PCS & 0.012 & .927 \\
TSK-1 & -0.077 & .563 \\
3 wk & -0.101 & .480 \\
$\quad$ PCS & -0.025 & .864 \\
TSK-11 & & \\
6 wk & -0.422 & $.009^{*}$ \\
PCS & -0.043 & .746 \\
TSK-11 & & \\
3 mo & -0.191 & .180 \\
PCS & -0.126 & .756 \\
TSK-11 & & \\
6 mo & -0.215 & .126 \\
PCS & -0.145 & .377 \\
TSK-11 & & $.004^{*}$ \\
1 y & -0.446 & $.021^{*}$ \\
$\quad$ PCS & -0.330 & \\
TSK-11 & & \\
\hline PCS, Pain Catastrophizing Scale; TSK-11, Tampa Scale for Kinesi- \\
ophobia-11. \\
*Indicates significance at $P<.05$.
\end{tabular}


Fig 2. Comparison of Pain Catastrophizing Scale scores between patients returning and failing to return to sport.

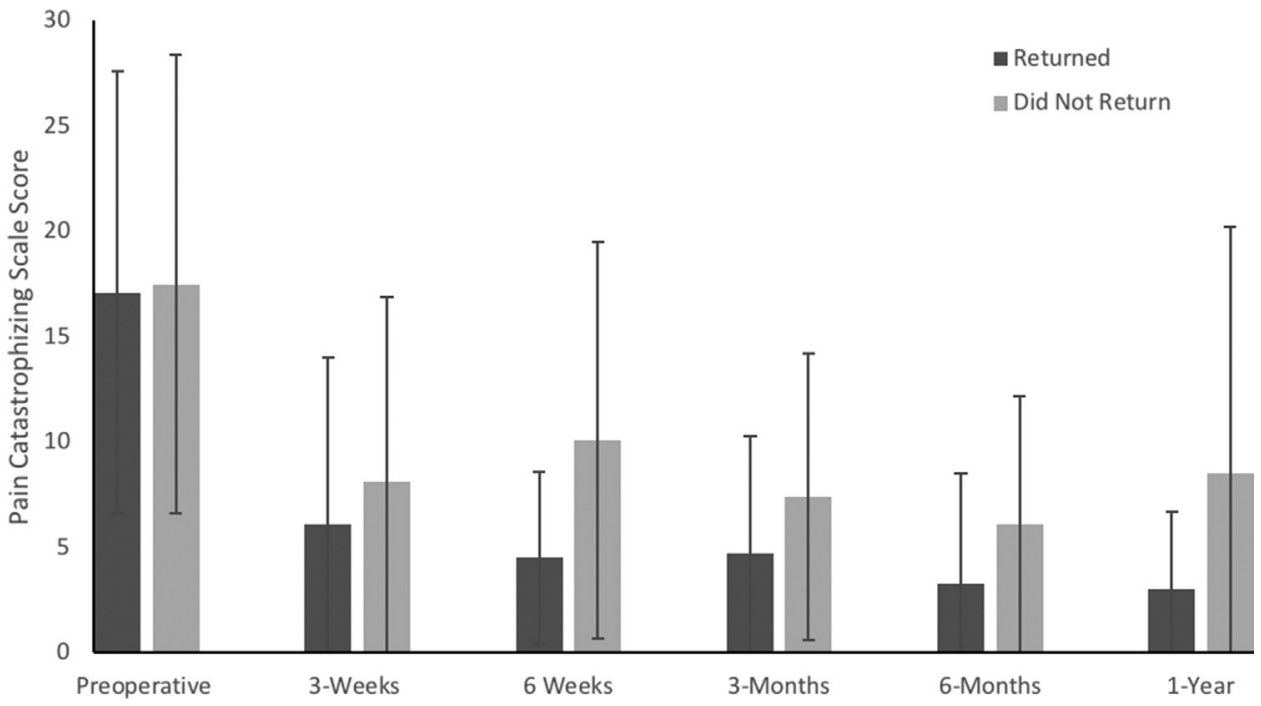

scores at 1-year postoperatively were greater in the patients who failed to RTS. Furthermore, pain catastrophizing and kinesiophobia were negatively correlated with achieving a CSO with regards to sporting function. Hip arthroscopy for the treatment of FAI has yielded improved patient outcomes for the vast majority of patients with a high rate of RTS. ${ }^{1-3,10,13}$ Despite this, there continues to be a subset of patients who are unable to RTS at a preinjury level. Patient-specific factors, including physical and mental characteristics, could influence a patient's ability to achieve clinical improvement following surgery. ${ }^{18,19,22,46}$

Fifty-eight athletes were included in the present study. Both kinesiophobia and pain catastrophizing scores improved from preoperative scores at each time point from 3 weeks to 1 year. There was an improvement in all PROs and a decrease in VAS pain at 2 years postoperatively, which is consistent with prior studies from this group. ${ }^{2}$ Physical limitations of the operative hip including hip pain was the most common reason for not returning to sport. The slightly lower rate of RTS, longer duration before return, and larger proportion of patients with continued pain is likely due a larger proportion of recreational athletes in this cohort compared with other studies assessing return to play in athletes. $^{47}$

Pain catastrophizing and kinesiophobia, or the exaggerated response to a given pain and the fear of reinjury, respectively, has been shown to result in inferior patient outcomes following orthopaedic surgery. ${ }^{48,49}$ Clapp et al. ${ }^{34}$ found that pain catastrophizing and kinesiophobia improved 1 year postoperatively

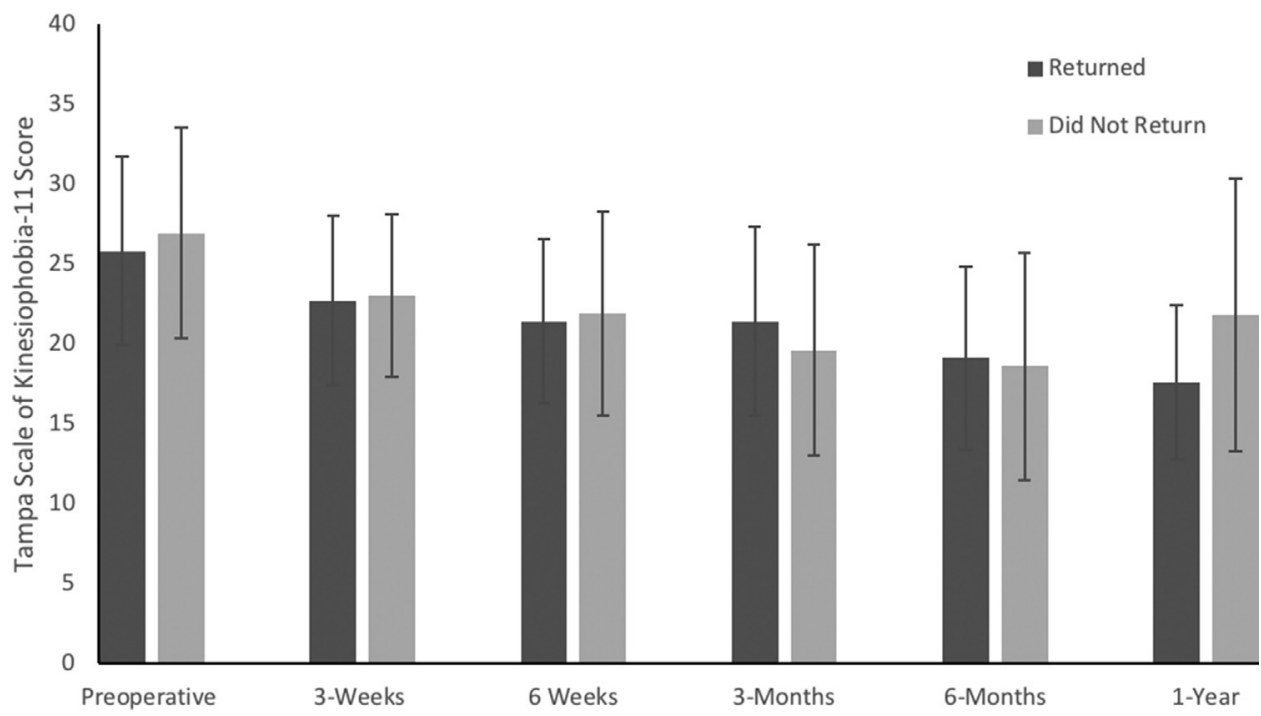

Fig 3. Comparison of Tampa Scale of Kinesiophobia-11 scores between patients returning and failing to return to sport. 


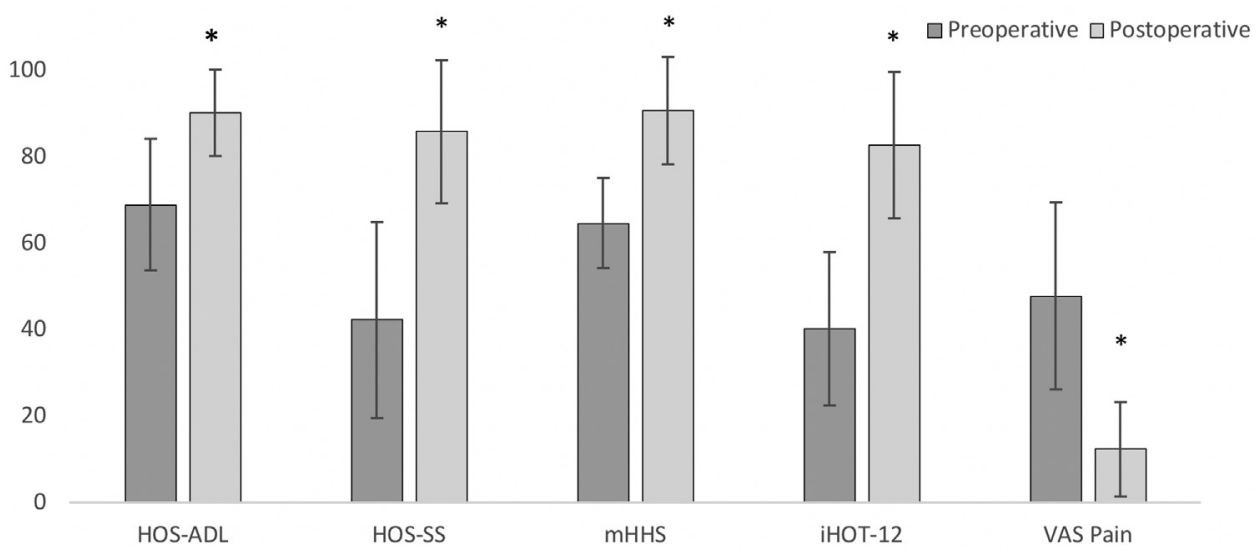

Fig 4. Comparison of preoperative and 2-year patient-reported outcomes. *Denotes significance at $P<.05$. (HOS-ADL, Hip Outcome Score Activities of Daily Living; HOS-SS, Hip Outcome Score Sport-Specific; iHOT-12, International Hip Outcome Tool12; mHHS, modified Harris Hip Score; VAS, visual analog scale.) and that pain catastrophizing scores were significantly greater in those who did not achieve MCID but kinesiophobia scores did not correlate with MCID achievement at 1 year. The current study demonstrated that patients with greater levels of kinesiophobia at 1 year postoperatively were less likely to RTS and achieve PASS. The fact that kinesiophobia does not correlate with patient-reported outcomes before RTS is not surprising and is consistent with previous studies. ${ }^{34}$ Once patients have been removed from the controlled environment of physical therapy, the fear of injury upon RTS is likely at its greatest and would affect both successful RTS and patient-reported outcomes.

Table 3. Correlation Analysis Between Achieving PASS and SCB for HOS-SS at 1-Year and PCS and TSK-11 Scores

\begin{tabular}{lcccc}
\hline & PASS $(r)$ & $P$ Value & SCB $(r)$ & $P$ Value \\
\hline Preoperative & & & & \\
$\quad$ PCS & 0.123 & .408 & -0.005 & .973 \\
TSK-11 & 0.013 & .928 & -0.028 & .850 \\
3 wk & & & & \\
PCS & -0.093 & .560 & 0.012 & .942 \\
TSK-11 & -0.060 & .705 & 0.151 & .339 \\
6 wk & & & & \\
PCS & -0.466 & $.001^{*}$ & -0.386 & $.010^{*}$ \\
TSK-11 & -0.117 & .449 & -0.155 & .316 \\
3 mo & & & & \\
PCS & -0.179 & .258 & -0.390 & $.011^{*}$ \\
TSK-11 & -0.140 & .377 & -0.300 & .054 \\
6 mo & & & & \\
PCS & -0.311 & $.043^{*}$ & -0.463 & $.002^{*}$ \\
TSK-11 & -0.087 & .578 & -0.186 & .234 \\
1 y & & & & \\
PCS & -0.493 & $.001^{*}$ & v0.487 & $.001^{*}$ \\
TSK-11 & -0.318 & $.031^{*}$ & -0.317 & $.032^{*}$
\end{tabular}

HOS-SS, Hip Outcome Score-Sports Subscale; PASS, Patient Acceptable Symptom State; PCS, Pain Catastrophizing Scale; SCB, substantial clinical benefit; TSK-11, Tampa Scale for Kinesiophobia-11.

*Indicates significance at $P<.05$.
Patients with lower pain catastrophizing scores at 6week and 1-year follow-up and lower kinesiophobia scores at 1-year follow-up were more likely to RTS following hip arthroscopy. Lower pain catastrophizing scores at 3 months, 6 months, and 1 year also were associated with an increased likelihood of achieving sports specific PASS. Following a structured physical therapy regimen has shown to improve patientreported outcomes following hip arthroscopy. ${ }^{50}$ These results signify that pain catastrophizing does not affect patient-reported outcomes early in the rehabilitation process, as patients are limited in physical activity. Pain catastrophizing has been shown to negatively influence physical therapy outcomes for other orthopaedic

Table 4. Correlation Analysis Between Achieving PASS and SCB for HOS-SS at 2-Year and PCS and TSK-11 Scores

\begin{tabular}{lrlll}
\hline & PASS $(r)$ & $P$ Value & SCB $(r)$ & $P$ Value \\
\hline Preoperative & & & & \\
$\quad$ PCS & -0.202 & .268 & 0.100 & .584 \\
TSK-11 & 0.056 & .759 & 0.054 & .769 \\
3 wk & & & & \\
$\quad$ PCS & -0.215 & .245 & -0.166 & .372 \\
$\quad$ TSK-1 & -0.085 & .650 & -0.005 & .977 \\
6 wk & & & & \\
PCS & -0.324 & .081 & -0.239 & .203 \\
TSK-11 & -0.246 & .190 & -0.155 & .414 \\
3 mo & & & & \\
PCS & -0.429 & $.020^{*}$ & -0.338 & .078 \\
TSK-11 & -0.024 & .903 & -0.147 & .447 \\
6 mo & & & & \\
PCS & -0.454 & $.010^{*}$ & -0.384 & .033 \\
TSK-11 & -0.318 & .082 & -0.334 & .066 \\
1 y & & & & \\
PCS & -0.572 & $.001^{*}$ & -0.549 & $.001^{*}$ \\
TSK-11 & -0.441 & $.012^{*}$ & -0.398 & $.024^{*}$ \\
\hline
\end{tabular}

HOS-SS, Hip Outcome Score-Sports Subscale; PASS, Patient Acceptable Symptom State; PCS, Pain Catastrophizing Scale; SCB, substantial clinical benefit; TSK-11, Tampa Scale for Kinesiophobia-11.

*Indicates significance at $P<.05$. 
pathologies such as osteoarthritis, and it is plausible that greater levels of pain catastrophizing would negatively affect therapy following hip arthroscopy for the treatment of FAI. ${ }^{51}$ As the intensity of physical therapy increases beginning at 6 weeks and progressively intensifies until RTS, it is no surprise that patients who are able to better perform in physical therapy would be more likely to RTS and achieve clinical improvement. These patients are likely able to prevent muscular imbalance and gait abnormalities associated with weakness in the operative extremity and feel more comfortable performing in sports-related activity than those who could not fully participate.

Further studies are necessary to determine how to improve physical therapy and ultimately patientreported outcomes and RTS for patients with pain catastrophizing and kinesiophobia. Moreover, it is important to discern interventions that may address or change these psychological traits to improve outcomes.

\section{Limitations}

There are some limitations in this study. First, multiple factors other than kinesiophobia and pain catastrophizing can affect patient-reported outcomes and RTS following hip arthroscopy. While there were no significant differences in age, ex, and BMI between the groups returning and failing to RTS, other confounding variables that may affect RTS were not controlled for. Second, all of the surgical procedures were performed by a single high-volume, fellowship-trained surgeon with extensive experience in hip arthroscopy, and the outcomes of this study may not be generalizable. In addition, a majority of patients failing to RTS cited physical limitation including hip pain, which was selfreported. Not all patients who did not to RTS were examined, and therefore, it is difficult to conclude whether their failure to return was due to real physical limitation or if it was a perceived or psychological limitation. Furthermore, there was no standardized assessment of patients' activity level with an objective instrument, and we relied on patients' self-reported levels of function.

\section{Conclusions}

Patient kinesiophobia and pain catastrophizing at 1year follow-up were negatively correlated with RTS and achievement of a CSO in sport related activities at 2-year follow-up.

\section{References}

1. Byrd JW, Jones KS. Arthroscopic management of femoroacetabular impingement in athletes. Am J Sports Med 2011;39:7s-13s (suppl).

2. Clapp IM, Nwachukwu BU, Beck EC, Jan K, Gowd AK, Nho SJ. Comparing outcomes of competitive athletes versus nonathletes undergoing hip arthroscopy for treatment of femoroacetabular impingement syndrome. Am J Sports Med 2020;48:159-166.

3. Ishoi L, Thorborg K, Kraemer O, Holmich P. Return to sport and performance after hip arthroscopy for femoroacetabular impingement in 18- to 30-year-old athletes: A cross-sectional cohort study of 189 athletes. Am J Sports Med 2018;46:2578-2587.

4. Bozic KJ, Chan V, Valone FH 3rd, Feeley BT, Vail TP. Trends in hip arthroscopy utilization in the United States. J Arthroplasty 2013;28:140-143.

5. Levy DM, Kuhns BD, Chahal J, Philippon MJ, Kelly BT, Nho SJ. Hip arthroscopy outcomes with respect to patient acceptable symptomatic state and minimal clinically important difference. Arthroscopy 2016;32: $1877-1886$.

6. Perets I, Hartigan DE, Chaharbakhshi EO, Ashberg L, Ortiz-Declet V, Domb BG. Outcomes of hip arthroscopy in competitive athletes. Arthroscopy 2017;33:1521-1529.

7. Byrd JW, Jones KS, Schmitz LM, Doner GP. Hip arthroscopy in the warrior athlete: 2 to 10 year outcomes. J Hip Preserv Surg 2016;3:68-71.

8. Riff AJ, Ukwuani G, Clapp I, Movassaghi K, Kelly DM, Nho SJ. High rate of return to high-intensity interval training after arthroscopic management of femoroacetabular impingement syndrome. Am J Sports Med 2018;46:2594-2600.

9. Alradwan H, Philippon MJ, Farrokhyar F, et al. Return to preinjury activity levels after surgical management of femoroacetabular impingement in athletes. Arthroscopy 2012;28:1567-1576.

10. Amenabar T, O'Donnell J. Return to sport in Australian football league footballers after hip arthroscopy and midterm outcome. Arthroscopy 2013;29:1188-1194.

11. Barastegui D, Seijas R, Alvarez-Diaz P, et al. Assessing long-term return to play after hip arthroscopy in football players evaluating risk factors for good prognosis. Knee Surg Sports Traumatol Arthrosc 2018;26:963-968.

12. Begly JP, Buckley PS, Utsunomiya H, Briggs KK, Philippon MJ. Femoroacetabular impingement in professional basketball players: Return to play, career length, and performance after hip arthroscopy. Am J Sports Med 2018;46:3090-3096.

13. Casartelli NC, Leunig M, Maffiuletti NA, Bizzini M. Return to sport after hip surgery for femoroacetabular impingement: A systematic review. Br J Sports Med 2015;49: 819-824.

14. Frank RM, Lee S, Bush-Joseph CA, Salata MJ, Mather RC 3rd, Nho SJ. Outcomes for Hip arthroscopy according to sex and age: A comparative matched-group analysis. J Bone Joint Surg Am 2016;98:797-804.

15. Perets I, Rybalko D, Chaharbakhshi EO, Mu BH, Chen AW, Domb BG. Minimum five-year outcomes of hip arthroscopy for the treatment of femoroacetabular impingement and labral tears in patients with obesity: A match-controlled study. J Bone Joint Surg Am 2018;100: 965-973.

16. Stone AV, Beck EC, Malloy $\mathrm{P}$, et al. Preoperative predictors of achieving clinically significant athletic functional status after hip arthroscopy for femoroacetabular impingement at minimum 2-year follow-up. Arthroscopy 2019;35:3049-3056.e3041. 
17. Sochacki KR, Brown L, Cenkus K, Di Stasi S, Harris JD, Ellis TJ. Preoperative depression is negatively associated with function and predicts poorer outcomes after hip arthroscopy for femoroacetabular impingement. Arthroscopy 2018;34:2368-2374.

18. Ayers DC, Franklin PD, Ring DC. The role of emotional health in functional outcomes after orthopaedic surgery: Extending the biopsychosocial model to orthopaedics: AOA critical issues. J Bone Joint Surg Am 2013;95:e165.

19. Flanigan DC, Everhart JS. Glassman AH. Psychological factors affecting rehabilitation and outcomes following elective orthopaedic surgery. J Am Acad Orthop Surg 2015;23:570.

20. Potter MQ, Wylie JD, Sun GS, Beckmann JT, Aoki SK. Psychologic distress reduces preoperative self-assessment scores in femoroacetabular impingement patients. Clin Orthop Relat Res 2014;472:1886-1892.

21. Stone AV, Malloy P, Beck EC, et al. Predictors of persistent postoperative pain at minimum 2 years after arthroscopic treatment of femoroacetabular impingement. Am J Sports Med 2019;47:552-559.

22. Martin RL, Christoforetti JJ, McGovern R, et al. The impact of depression on patient outcomes in hip arthroscopic surgery. Orthop J Sports Med 2018;6: 2325967118806490.

23. Lansdown DA, Ukwuani G, Kuhns B, Harris JD, Nho SJ. Self-reported mental disorders negatively influence surgical outcomes after arthroscopic treatment of femoroacetabular impingement. Orthop J Sports Med 2018;6: 2325967118773312.

24. Filardo G, Roffi A, Merli G, et al. Patient kinesiophobia affects both recovery time and final outcome after total knee arthroplasty. Knee Surg Sports Traumatol Arthrosc 2016;24:3322-3328.

25. Domenech J, Sanchis-Alfonso V, Lopez L, Espejo B. Influence of kinesiophobia and catastrophizing on pain and disability in anterior knee pain patients. Knee Surg Sports Traumatol Arthrosc 2013;21:1562-1568.

26. Leeuw M, Goossens ME, Linton SJ, Crombez G, Boersma K, Vlaeyen JW. The fear-avoidance model of musculoskeletal pain: Current state of scientific evidence. J Behav Med 2007;30:77-94.

27. Sullivan MJL, Bishop SR, Pivik J. The Pain Catastrophizing Scale: Development and validation. Psychol Assess 1995;7:524-532.

28. Woby SR, Roach NK, Urmston M, Watson PJ. Psychometric properties of the TSK-11: A shortened version of the Tampa Scale for Kinesiophobia. Pain 2005;117: 137-144.

29. Kim HJ, Park JW, Chang BS, Lee CK, Yeom JS. The influence of catastrophising on treatment outcomes after surgery for lumbar spinal stenosis. Bone Joint J 2015;97-B:54.

30. Chmielewski TL, Jones D, Day T, Tillman SM, Lentz TA, George SZ. The association of pain and fear of movement/ reinjury with function during anterior cruciate ligament reconstruction rehabilitation. J Orthop Sports Phys Ther 2008;38:746-753.

31. Brown ML, Plate JF, Von Thaer S, et al. Decreased range of motion after total knee arthroplasty is predicted by the tampa scale of kinesiophobia. J Arthroplasty 2016;31: 793-797.
32. Lentz TA, Zeppieri G Jr, Tillman SM, et al. Return to preinjury sports participation following anterior cruciate ligament reconstruction: Contributions of demographic, knee impairment, and self-report measures. J Orthop Sports Phys Ther 2012;42:893-901.

33. Nwachukwu BU, Adjei J, Rauck RC, et al. How much do psychological factors affect lack of return to play after anterior cruciate ligament reconstruction? A systematic review. Orthop J Sports Med 2019;7: 2325967119845313.

34. Clapp IM, Nwachukwu BU, Beck EC, et al. What is the role of kinesiophobia and pain catastrophizing in outcomes after hip arthroscopy for femoroacetabular impingement syndrome? Arthrosc Sports Med Rehabil 2020;2:e97-e104.

35. Griffin DR, Dickenson EJ, O'Donnell J, et al. The Warwick Agreement on femoroacetabular impingement syndrome (FAI syndrome): An international consensus statement. Br J Sports Med 2016;50:1169-1176.

36. Clohisy JC, Carlisle JC, Beaulé PE, et al. A systematic approach to the plain radiographic evaluation of the young adult hip. J Bone Joint Surg Am 2008;90:47-66 (suppl 4).

37. Frank RM, Lee S, Bush-Joseph CA, Kelly BT, Salata MJ, Nho SJ. Improved outcomes after hip arthroscopic surgery in patients undergoing T-capsulotomy with complete repair versus partial repair for femoroacetabular impingement: A comparative matched-pair analysis. Am J Sports Med 2014;42:2634-2642.

38. Harris JD, Slikker W 3rd, Gupta AK, McCormick FM, Nho SJ. Routine complete capsular closure during hip arthroscopy. Arthrosc Tech 2013;2:e89-e94.

39. Beck EC, Alter T, Mehta N, et al. Contemporary hip capsular management and closure using a suture passing device. Arthrosc Tech 2019;8:e947-e952.

40. Malloy P, Gray K, Wolff AB. Rehabilitation after hip arthroscopy: A movement control-based perspective. Clin Sports Med 2016;35:503-521.

41. Martin RL, Kelly BT, Philippon MJ. Evidence of validity for the Hip Outcome Score. Arthroscopy 2006;22: 1304-1311.

42. Chahal J, Van Thiel GS, Mather RC 3rd, et al. The Patient Acceptable Symptomatic State for the modified Harris Hip Score and Hip Outcome Score among patients undergoing surgical treatment for femoroacetabular impingement. Am J Sports Med 2015;43:1844-1849.

43. Griffin DR, Parsons N, Mohtadi NG, Safran MR. A short version of the International Hip Outcome Tool (iHOT-12) for use in routine clinical practice. Arthroscopy 2012;28: 611-616; quiz 616-618.

44. Nwachukwu BU, Beck EC, Kunze KN, Chahla J, Rasio J, Nho SJ. Defining the clinically meaningful outcomes for arthroscopic treatment of femoroacetabular impingement syndrome at minimum 5-year follow-up. Am J Sports Med 2020;48:901-907.

45. Chan YH. Biostatistics 103: qualitative data - tests of independence. Singapore Med J 2003;44:498-503.

46. Sorel JC, Veltman ES, Honig A, Poolman RW. The influence of preoperative psychological distress on pain and function after total knee arthroplasty. Bone Joint $J$ 2019;101-B:7-14. 
47. O'Connor M, Minkara AA, Westermann RW, Rosneck J, Lynch TS. Return to play after hip arthroscopy: A systematic review and meta-analysis. Am J Sports Med 2018:46:2780-2788.

48. Papaioannou M, Skapinakis P, Damigos D, Mavreas V, Broumas G, Palgimesi A. The role of catastrophizing in the prediction of postoperative pain. Pain Med 2009;10: 1452-1459.

49. Riddle DL, Wade JB, Jiranek WA, Kong X. Preoperative pain catastrophizing predicts pain outcome after knee arthroplasty. Clin Orthop Relat Res 2010;468: 798-806.

50. Domb BG, Sgroi TA, VanDevender JC. Physical therapy protocol after hip arthroscopy: Clinical guidelines supported by 2-year outcomes. Sports Health 2016;8: 347-354.

51. Uckun AC, Donmez BK, Yurdakul FG, Garip Y, Bodur H. The role of pain catastrophizing and depression in the outcomes of physical therapy in a prospective osteoarthritis cohort. Pain Physician 2020;23:209-218. 